\title{
Effects of effective microorganisms biochar-based fertilizer on photosynthetic characteristics and chlorophyll content of flue-cured tobacco under water-saving irrigation strategies
}

\author{
Xiuneng $\mathrm{Li}^{1}$, Xiaohou Shao ${ }^{1 *}$, Fuzhang Ding ${ }^{2}$, Youbo Yuan ${ }^{2}$, Rongqi $\mathrm{Li}^{1}$, Xu Yang ${ }^{1}$, Chao Gao ${ }^{1}$, \\ and Qisong Miao ${ }^{1}$
}

\begin{abstract}
${ }^{1}$ Hohai University, College of Agricultural Engineering, 210098, Nanjing, China. *Corresponding author (hohaisxh@126.com). ${ }^{2}$ Institute of Tobacco Science in Guizhou Province, 550081, Guiyang, China.
\end{abstract}

Received: 12 March 2020; Accepted: 16 May 2020; doi:10.4067/S0718-58392020000300422

\begin{abstract}
Effective microorganism biochar-based fertilizer (EMBF) can improve the physiological properties of tobacco (Nicotiana tabacum L.) In this study, the irrigation and EMBF rates were applied as factors that influence the photosynthetic characteristics and chlorophyll content of tobacco. The experiment involved 12 treatments: CK1-CK3, T1-T3, T4-T6, and T7-T9; these four groups represented 0, 100, 300, and $600 \mathrm{~g} \mathrm{EMBF} \mathrm{pot}^{-1}$, respectively. Each group was irrigated at rates of 40,80 , and $120 \mathrm{~L} \mathrm{pot}^{-1}$. When comparing with the control treatment $\mathrm{CK}$, results showed that net photosynthetic rate $\left(\mathrm{P}_{\mathrm{n}}\right)$, stomatal conductance $\left(\mathrm{g}_{\mathrm{s}}\right)$, intercellular $\mathrm{CO}_{2}$ concentration $\left(\mathrm{C}_{\mathrm{i}}\right)$, transpiration rate $\left(\mathrm{T}_{\mathrm{r}}\right)$, and soil plant analysis development (SPAD) increased by $8.21 \%-107.03 \%, 18.78 \%-118.27 \%, 18.78 \%-118.27 \%, 7.24 \%-104.15 \%$, and $3.47 \%-$ $69.09 \%$, respectively, after EMBF application. The $\mathrm{P}_{n}, \mathrm{~g}_{s}, \mathrm{C}_{\mathrm{i}}$ and $\mathrm{T}_{\mathrm{r}}$ at the growth and maturity stages were highly significant $(P<0.01)$ and positively correlated with EMBF application. The $P_{n}, g_{s}$, and $T_{r}$ were significant $(P<0.05)$ and positively correlated with irrigation, and $\mathrm{C}_{\mathrm{i}}$ was less affected by irrigation $(\mathrm{P}>0.05)$. The SPAD value of flue-cured tobacco at three growing stages was highly significant $(\mathrm{P}<0.01)$ and positively correlated with the irrigation and fertilization rates. The SPAD values at the growth and maturity stages were higher than those at the rooting stage by $46.73 \%-79.2 \%$ and $2.21 \%$ $46.17 \%$, respectively. Furthermore, the $80 \mathrm{~L} \mathrm{pot}^{-1}$ irrigation rate combined with $300 \mathrm{~g} \mathrm{EMBF} \mathrm{pot}^{-1}$ is the best water and fertilizer combination. The results of this study might provide theoretical and practical guidance for growing flue-cured tobacco in production areas.
\end{abstract}

Key words: Chlorophyll content, EMBF, flue-cured tobacco, Nicotiana tabacum, photosynthetic characteristics.

\section{INTRODUCTION}

Tobacco (Nicotiana tabacum L.) is an important cash crop worldwide, and China is one of the largest producers (Kulik et al., 2017). Water and fertilizer are the two main factors affecting the growth, yield, and quality of flue-cured tobacco, and adjusting the water-fertilizer application rate is essential for controlling the yield and quality of flue-cured tobacco (Chen et al., 2017; Xue et al., 2019). In recent years, water resources have been scarce in China's major tobacco-growing areas, and their spatial and temporal distribution has been uneven (Zhang et al., 2019a). In addition, most of the water-fertilizer management approaches were used to achieve the goal of high yielding flue-cured tobacco. The long-term application of chemical fertilizers deteriorates soil physical properties, decreases fertility, and causes soil compaction (Xie et al., 2019). Therefore, studying a new water retention fertilizer and exploring the effect of a water-fertilizer interaction mechanism is an effective method to improve the water and fertilizer use efficiency quality, and yield of flue-cured tobacco. 
There are currently many reports on flue-cured tobacco base fertilizers. Biochar has a strong adsorption ability because of its great porosity and high specific surface area (Zhu et al., 2018). Biochar-based fertilizer prepared with biochar as a fertilizer carrier can promote tobacco growth and increase its quality (Qin et al., 2018; Chen et al., 2019; Li et al., 2019a). Compared with conventional fertilization, adding biochar-based fertilizer can significantly increase total sugar in tobacco leaves (Wang et al., 2019), chlorophyll content, fertilizer rate (Chen et al., 2019), and net photosynthetic rate $\left(\mathrm{P}_{\mathrm{n}}\right)$ in leaves (Li et al., 2019b). Some studies have shown that applying large amounts of biochar-based fertilizer would not improve tobacco leaf quality (Zhang et al., 2019b). Ye et al. (2015) showed that the highest nicotine content and lowest sensory quality of tobacco leaf in treatment conventional fertilization and biochar $900 \mathrm{~kg} \mathrm{hm}^{-2} \mathrm{ha}^{-1}$ might be due to the increase of the $\mathrm{N}$ fertilizer rate after an excessive biochar application. Effective microorganisms (EM) are cultures of coexisting beneficial microorganisms, including up to 80 different species, which predominantly consist of photosynthetic and lactic acid bacteria, yeast, and actinomycete species (Daly and Stewart, 1999). They are a soil activator and improve soil structure, organic matter management, and nutrient cycling, which complement efforts to reduce the reliance on synthetic fertilizers and pesticides; they have excellent development prospects in agriculture, animal husbandry, breeding, and environmental protection (Talaat et al., 2015). Bokashi is the growth medium for microorganisms and provides a suitable micro-environment for EM in the soil; EM-bokashi is an anaerobic fermentation product from solid agricultural byproducts and EM (Higa and Parr, 1994; Shin et al., 2017). Hu and Qi (2013) showed that long-term EM application combined with compost enhanced wheat straw biomass, grain yields, and straw and grain nutrition. Dai et al. (2019) showed that the EM treatment markedly promoted $\mathrm{P}_{\mathrm{n}}$, stomatal conductance $\left(\mathrm{g}_{\mathrm{s}}\right)$, and transpiration rate $\left(\mathrm{T}_{\mathrm{r}}\right)$ of Quercus shumardii, and notably improved the leaf chlorophyll mass fraction.

Although the above studies have achieved satisfactory results, the water retention performance of EM biochar-based fertilizer (EMBF) and the influence of EMBF on agronomic traits, photosynthetic characteristics, quality, and yield of flue-cured tobacco are still unclear. Therefore, the aim of this study was to evaluate the effect of different water and EMBF application rates on the physiological indices of flue-cured tobacco (photosynthetic characteristics and chlorophyll content) and evaluate the water retention ability of EMBF.

\section{MATERIALS AND METHODS}

\section{Experimental site}

The experiment was conducted in a plastic covered greenhouse in the Vegetables and Flowers Institute of Hohai University research base $\left(31^{\circ} 43^{\prime} \mathrm{N}, 118^{\circ} 46^{\prime} \mathrm{E}\right)$, Nanjing, China, in 2019. The research area belongs to the north subtropical monsoon climate zone with an average annual temperature of $15.4^{\circ} \mathrm{C}$, average annual precipitation of $1106.5 \mathrm{~mm}$, and an average frost-free period of $224 \mathrm{~d}$. The soil in the test site was yellow-brown soil with a thick texture. The soil physicochemical properties were $\mathrm{pH} 5.87,14.2 \mathrm{~g} \mathrm{~kg}^{-1}$ organic matter content, $19.72 \mathrm{mg} \mathrm{kg}^{-1}$ available $\mathrm{P}, 174.23 \mathrm{mg} \mathrm{kg}^{-1}$ available K, 121.65 $\mathrm{mg} \mathrm{kg}^{-1}$ available $\mathrm{N}$, and 0-60 $\mathrm{cm}$ depth soil density of $1.35 \mathrm{~g} \mathrm{~cm}^{-3}$.

\section{Experimental design}

The experiment was carried out in plastic flower pots (360 mm diameter, $300 \mathrm{~mm}$ height). 'Yunyan 87' was selected as the tobacco (Nicotiana tabacum L.) seedling, and soil was taken from the experimental greenhouse. The experiment divided the growth cycle of tobacco into three stages: rooting stage ( $35 \mathrm{~d}$ after seedling stage), growth stage (36-65 $\mathrm{d}$ after transplanting), and maturity stage (66 d after harvest). The experiment consisted of 12 treatments: CK1-CK3, T1-T3, T4T6, and T7-T9; the four groups of treatments received 0, 100,300, and $600 \mathrm{~g} \mathrm{pot}^{-1}$ of effective microorganism biocharbased fertilizer (EMBF), respectively, and each group was irrigated with 40, 80, and $120 \mathrm{~L} \mathrm{pot}^{-1}$. Each treatment was in triplicate. During the transplanting stage, $2 \mathrm{~L}$ of water were applied to each pot in all treatments to stabilize the roots. The amount of irrigation was distributed according to the rooting, growth, and maturity stages of flue-cured tobacco, which accounted for $30 \%, 40 \%$, and $30 \%$ of the total irrigation rate, respectively, and watering occurred every $5 \mathrm{~d}$. The fertilizer used is a special base fertilizer for flue-cured tobacco $\left(\mathrm{N}: \mathrm{P}_{2} \mathrm{O}_{5}: \mathrm{K}_{2} \mathrm{O}\right.$ 9:13:22) and a biochar-based compound fertilizer $\left(\mathrm{N}: \mathrm{P}_{2} \mathrm{O}_{5}: \mathrm{K}_{2} \mathrm{O}\right.$ 9:11:18) (SEEK Bio-Technology, Shanghai, China). The EM-bokashi was produced by diluting the EM stock solution 50 to 100 times and a mixed fermentation with rice hulls and distilled water for 5 to $7 \mathrm{~d}$. The EM-Bokashi and EM stock solution were produced by EMRO Environmental Protection Biotechnology (Nanjing, China). One tonne of biochar-based compound fertilizer and $15 \mathrm{~kg}$ of EM-bokashi were mixed thoroughly. During mixing, the EM stock 
solution, which was diluted 100 times, was sprayed on the surface of the compost at $20 \mathrm{~kg}$ dilution per tonne of compost. The compost was covered with a film and fermented for 3 to $5 \mathrm{~d}$ to produce EMBF. The hole fertilization method was used and the special base fertilizer rate for flue-cured tobacco was $100 \mathrm{~g} \mathrm{pot}^{-1}$. The fertilization and irrigation rates for each treatment are shown in Table 1.

\section{Main tested indices and methods}

The photosynthetic characteristics of flue-cured tobacco were measured with a portable photosynthesis system (TPS-2, PP Systems, Amesbury, Massachusetts, USA). The fifth leaf from the top of the tobacco plant was selected between 09:00 and 11:00 $\mathrm{h}$ in fine weather. The measured leaf was the most recently fully expanded and its color was uniform. Light intensity was controlled at $800 \mu \mathrm{mol} \mathrm{m} \mathrm{m}^{-2} \mathrm{~s}^{-1}$. Measured characteristics included net photosynthetic rate $\left(\mathrm{P}_{\mathrm{n}}\right)$, stomatal conductance $\left(\mathrm{g}_{\mathrm{s}}\right)$, intercellular $\mathrm{CO}_{2}$ concentration $\left(\mathrm{C}_{\mathrm{i}}\right)$, and transpiration rate $\left(\mathrm{T}_{\mathrm{r}}\right)$. Leaves free of pests, physiological lesions, and mechanical damage were sampled. The first measurement was taken in the middle of the leaf and avoiding the veins; afterward, a measurement was taken at $3 \mathrm{~cm}$ on the left and right sides of the first sampling position. The error of the three soil plant analysis development (SPAD) values should be within 1 and the mean represented by the SPAD value of this leaf. The soil physicochemical properties were measured following the methods described by Li et al. (2008). A one-way ANOVA with Duncan's multiple range test was used to assess significant differences in the photosynthetic characteristics and SPAD, and Pearson's chi-squared test was used to analyze the correlation. All data in this experiment were processed with Origin 9.5 (OriginLab Corporation, Northampton, Massachusetts, USA), SPSS 17.0 (IBM, Armonk, New York, USA), and Excel 2019 software.

\section{RESULTS}

\section{Net photosynthetic rate $\left(\mathbf{P}_{\mathrm{n}}\right)$}

The photosynthetic characteristics of flue-cured tobacco were measured at the growth and maturity stages. The effects of different EMBF and irrigation rates on $P_{n}$ of flue-cured tobacco are shown in Figure 1. The highest $P_{n}$ was obtained in T9 at the growth stage with $19.57 \mu \mathrm{mol} \mathrm{m} \mathrm{m}^{-2} \mathrm{~s}^{-1}$, followed by T5 with $19.43 \mu \mathrm{mol} \mathrm{m}^{-2} \mathrm{~s}^{-1}$. The $\mathrm{P}_{\mathrm{n}}$ at the maturity stage was the highest in T5, followed by T6 with values of 12.77 and $10.97 \mu \mathrm{mol} \mathrm{m}^{-2} \mathrm{~s}^{-1}$, respectively. The $\mathrm{P}_{\mathrm{n}}$ of CK1 at the growth and maturity stages was 12.33 and $5.10 \mu \mathrm{mol} \mathrm{m} \mathrm{m}^{-2} \mathrm{~s}^{-1}$, respectively; these values were significantly $(\mathrm{P}<0.05)$ lower than in other treatments. Compared with the control CK, $\mathrm{P}_{\mathrm{n}}$ at the growth and maturity stages increased by $8.21 \%-40.28 \%$ and 36.6\%-107.03\%, respectively, after EMBF application. In the CK treatments with $100 \mathrm{~g}$, and $600 \mathrm{~g}$ fertilizer, $\mathrm{P}_{\mathrm{n}}$ at the growth stage increased as irrigation increased. In the $300 \mathrm{~g}$ fertilizer treatment, $\mathrm{P}_{\mathrm{n}}$ of the $80 \mathrm{~L}$ (medium) irrigation treatment T5 was $32.18 \%$ higher than the $40 \mathrm{~L}$ (low) irrigation treatment T4. However, it was nonsignificantly different from the $120 \mathrm{~L}$ (high) irrigation treatment T6 $(\mathrm{P}>0.05)$. For the same irrigation rate, $\mathrm{P}_{\mathrm{n}}$ at the growth stage increased as fertilization increased, and T9 had the highest value. There was a positive correlation between the irrigation and fertilization rates and $\mathrm{P}_{\mathrm{n}}$ at the growth stage of flue-cured tobacco.

Table 1. Irrigation and fertilization schemes for each treatment.

\begin{tabular}{|c|c|c|c|c|c|}
\hline \multirow[b]{2}{*}{ Treatment } & \multirow[b]{2}{*}{ EMBF } & \multicolumn{3}{|c|}{ Amount of irrigation at each growth stage } & \multirow{2}{*}{$\begin{array}{l}\text { Total irrigation } \\
\text { rate }\end{array}$} \\
\hline & & Rooting & Growth & Maturity & \\
\hline & $\mathrm{g} \mathrm{pot}^{-1}$ & $\longrightarrow$ & $\mathrm{L} \mathrm{pot}^{-1} \cdot \mathrm{time}^{-1}$ & - & $\mathrm{L}$ pot $^{-1}$ \\
\hline CK1 & 0 & 1.5 & 2.0 & 1.5 & 40 \\
\hline CK2 & 0 & 3.0 & 4.0 & 3.0 & 80 \\
\hline CK3 & 0 & 4.5 & 6.0 & 4.5 & 120 \\
\hline $\mathrm{T} 1$ & 100 & 1.5 & 2.0 & 1.5 & 40 \\
\hline $\mathrm{T} 2$ & 100 & 3.0 & 4.0 & 3.0 & 80 \\
\hline $\mathrm{T} 3$ & 100 & 4.5 & 6.0 & 4.5 & 120 \\
\hline $\mathrm{T} 4$ & 300 & 1.5 & 2.0 & 1.5 & 40 \\
\hline $\mathrm{T} 5$ & 300 & 3.0 & 4.0 & 3.0 & 80 \\
\hline T6 & 300 & 4.5 & 6.0 & 4.5 & 120 \\
\hline $\mathrm{T} 7$ & 600 & 1.5 & 2.0 & 1.5 & 40 \\
\hline T8 & 600 & 3.0 & 4.0 & 3.0 & 80 \\
\hline T9 & 600 & 4.5 & 6.0 & 4.5 & 120 \\
\hline
\end{tabular}

EMBF: Effective microorganism biochar-based fertilizer. 
Figure 1. Effect of different treatments on the net photosynthetic rate $\left(P_{n}\right)$.

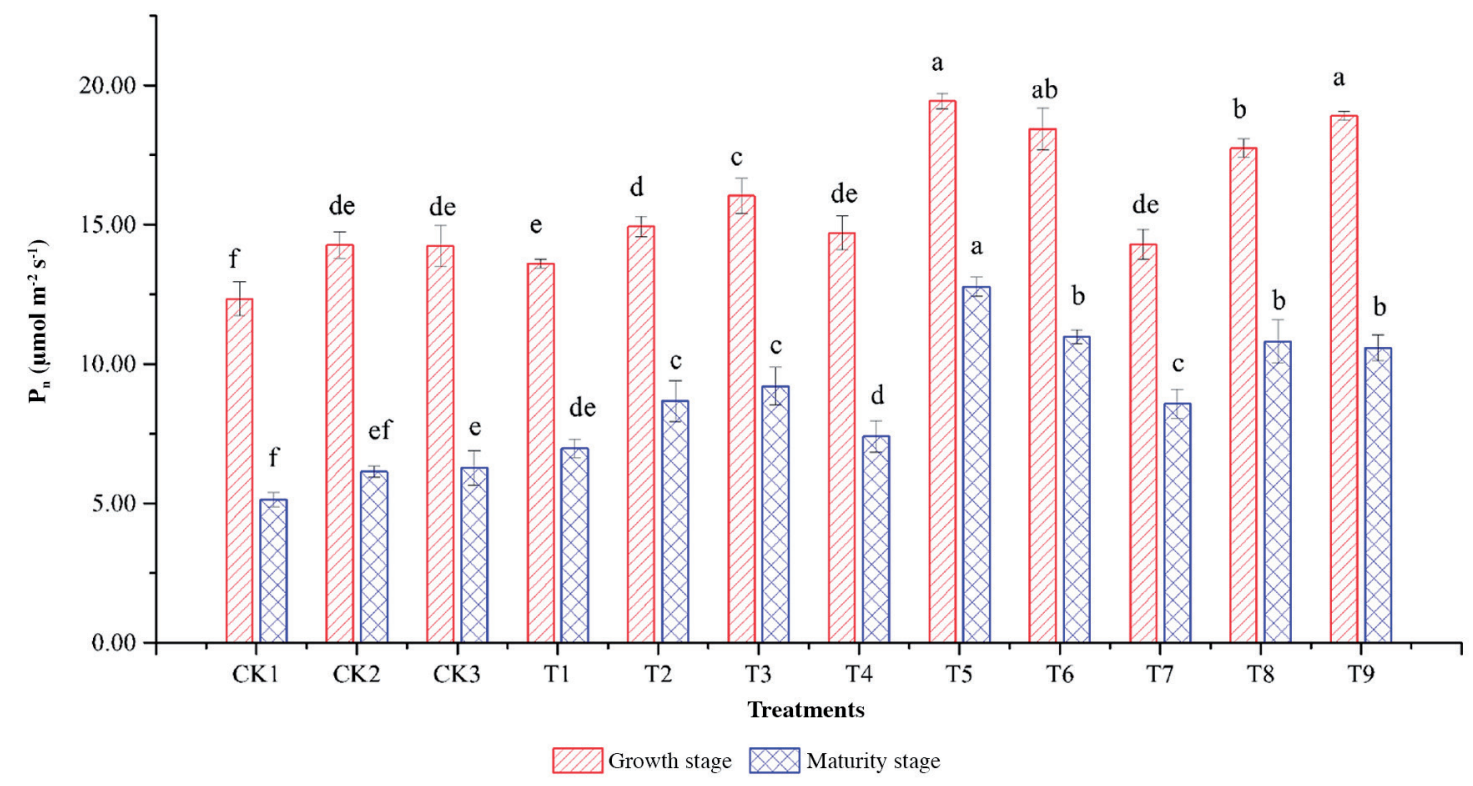

Different letters above the bars indicate significant differences $(\mathrm{P}<0.05)$ between biochar rates.

Treatments CK1-CK3, T1-T3, T4-T6, and T7-T9: Each group received 0, 100, 300, and 600 g effective microorganism biochar-based fertilizer pot $^{-1}$, respectively, and 40,80, and $120 \mathrm{~L}$ irrigation pot $^{-1}$, respectively.

The $P_{n}$ at the maturity stage decreased more than at the growth stage. The $P_{n}$ of the CK, 100, 300, and $600 \mathrm{~g}$ fertilization treatments decreased by $55.97 \%-58.38 \%, 41.96 \%-48.77 \%, 34.31 \%-49.66 \%$, and $39.10 \%-44.09 \%$, respectively. Under the same fertilization application conditions, $\mathrm{P}_{\mathrm{n}}$ of the CK and $100 \mathrm{~g}$ fertilization treatments increased as irrigation increased, whereas the 300 and $600 \mathrm{~g}$ fertilization treatments increased and then decreased. Treatment T5 had the highest $\mathrm{P}_{\mathrm{n}}$, and there was a significant difference with other treatments. Under the same irrigation rate, $\mathrm{P}_{\mathrm{n}}$ at the growth stage with $40 \mathrm{~L}$ irrigation increased as the fertilizer application increased. Among treatments, T7 had the highest value. Under 80 and $120 \mathrm{~L}$ irrigation, $\mathrm{P}_{\mathrm{n}}$ increased and then decreased as the fertilizer application increased, and the highest value was for treatment T5.

\section{Stomatal conductance $\left(\mathrm{g}_{\mathrm{s}}\right)$}

The effects of different EMBF fertilization and irrigation rates on $g_{s}$ of flue-cured tobacco are shown in Figure 2. The highest $\mathrm{g}_{\mathrm{s}}$ was obtained in T9 at the growth stage with $538.67 \mathrm{mmol} \mathrm{m} \mathrm{m}^{-2} \mathrm{~s}^{-1}$, followed by $\mathrm{T} 5$ with a value of $496.67 \mathrm{mmol} \mathrm{m}^{-2} \mathrm{~s}^{-1}$. Treatment CK1 had the lowest value at only $305.33 \mathrm{mmol} \mathrm{m} \mathrm{m}^{-2} \mathrm{~s}^{-1}$. In contrast to the growth stage, $g_{s}$ at the maturity stage had the highest value in T5 with $380.33 \mathrm{mmol} \mathrm{m}^{-2} \mathrm{~s}^{-1}$. Treatment $\mathrm{T} 9$ was second with $350.33 \mathrm{mmol} \mathrm{m}^{-2} \mathrm{~s}^{-1}$ and CK1 had the lowest value with only $146.67 \mathrm{mmol} \mathrm{m}^{-2} \mathrm{~s}^{-1}$. Compared with the control CK, $\mathrm{g}_{\mathrm{s}}$ at the growth and maturity stages increased by $10.17 \%-48.12 \%$ and $29.91 \%-109.36 \%$, respectively, after EMBF application. In the $\mathrm{CK}$ and 100 and $600 \mathrm{~g}$ fertilization treatments, $\mathrm{g}_{\mathrm{s}}$ at the growth stage increased as irrigation increased. For the $300 \mathrm{~g}$ fertilization rate, $g_{s}$ at the growth stage increased and then decreased as irrigation increased, and $g_{s}$ of $T 5$ had the highest value. Under the same irrigation condition, $g_{s}$ at the growth stage of the 40 and 120 L irrigation treatments was positively correlated with the fertilization rate. However, $\mathrm{g}_{\mathrm{s}}$ in the $80 \mathrm{~L}$ irrigation treatment increased then decreased and $\mathrm{T} 5$ had the highest value.

The $\mathrm{g}_{\mathrm{s}}$ value at the maturity stage decreased more than at the growth stage. The $\mathrm{g}_{\mathrm{s}}$ values of CK, 100, 300, and $600 \mathrm{~g}$ fertilization rates decreased by $36.57 \%-51.97 \%, 25.21 \%-44.48 \%, 23.42 \%-29.05 \%$, and $20.79 \%-34.96 \%$, respectively. Under the same fertilizer application conditions, $\mathrm{g}_{\mathrm{s}}$ at the maturity stage of $\mathrm{CK}, 100$, and $600 \mathrm{~g}$ fertilization rates increased as irrigation increased. At the $300 \mathrm{~g}$ fertilization rate, $\mathrm{g}_{\mathrm{s}}$ at the maturity stage increased and then decreased; $\mathrm{T} 5 \mathrm{had}$ the highest value and there was a significant difference with other treatments $(\mathrm{P}<0.05)$. Under the same irrigation condition, $\mathrm{g}_{\mathrm{s}}$ treated with 40 and $120 \mathrm{~L}$ irrigation was positively correlated with the fertilization rate, while the $80 \mathrm{~L}$ irrigation treatment increased and then decreased. 
Figure 2. Effect of different treatments on stomatal conductance $\left(\mathrm{g}_{\mathrm{s}}\right)$.

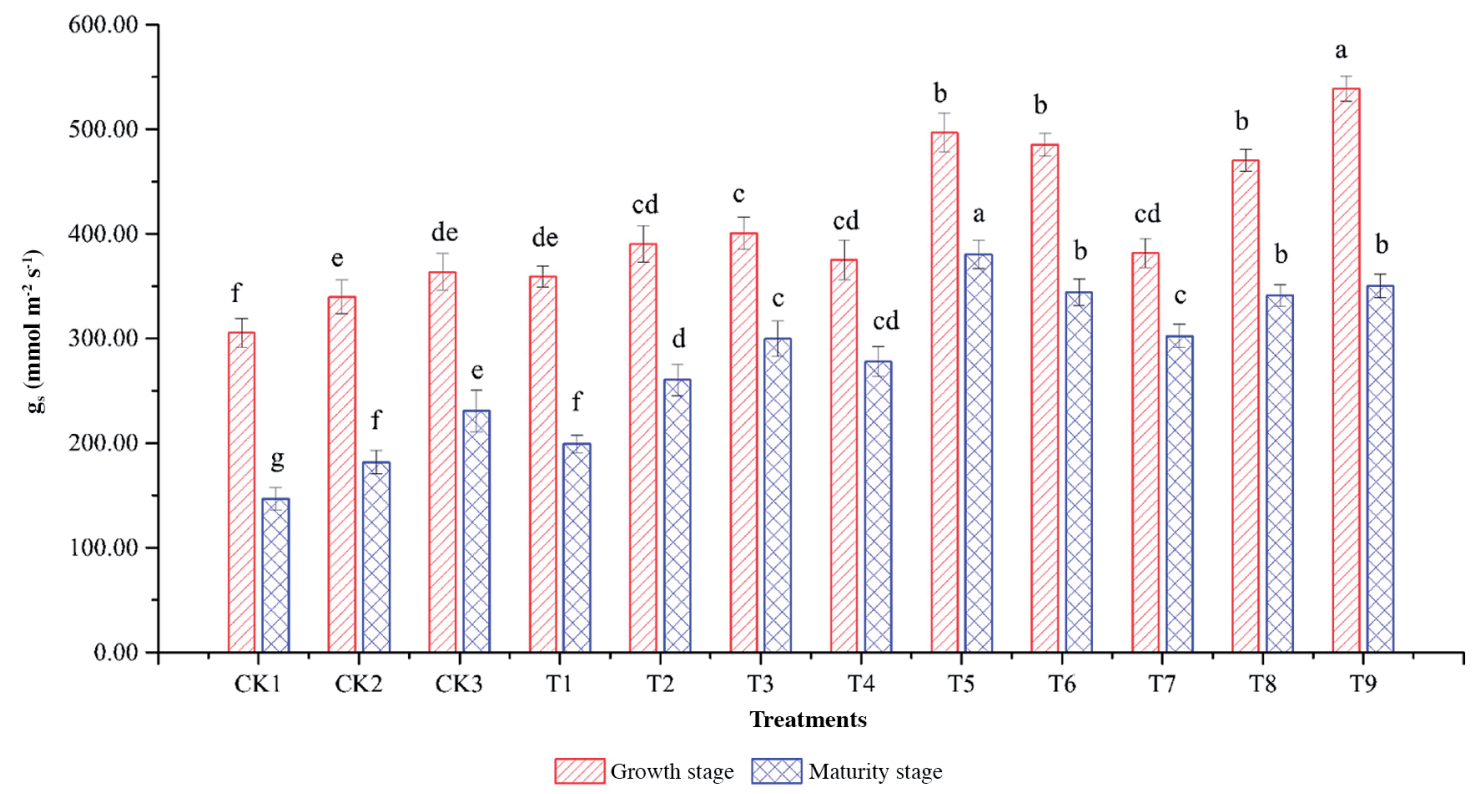

Different letters above the bars indicate significant differences $(\mathrm{P}<0.05)$ between biochar rates.

Treatments CK1-CK3, T1-T3, T4-T6, and T7-T9: Each group received 0, 100, 300, and 600 g effective microorganism biochar-based fertilizer pot $^{-1}$, respectively, and 40, 80, and $120 \mathrm{~L}_{\text {irrigation }}$ pot $^{-1}$, respectively.

\section{Intercellular $\mathrm{CO}_{2}$ concentration $\left(\mathrm{C}_{\mathrm{i}}\right)$}

The effects of different EMBF and irrigation rates on $\mathrm{C}_{\mathrm{i}}$ of flue-cured tobacco are shown in Figure 3 . The highest $\mathrm{C}_{\mathrm{i}}$ value was obtained in T5 at the growth stage with $416.33 \mu \mathrm{mol} \mathrm{mol}^{-1}$, followed by T8 with $389.67 \mu \mathrm{mol} \mathrm{mol}^{-1}$. Treatment CK1 had the lowest value with only $229 \mu \mathrm{mol} \mathrm{mol}^{-1}$. The same occurred for the growth stage, $\mathrm{C}_{\mathrm{i}}$ at the maturity stage had the highest value in T5 with $302.67 \mu \mathrm{mol} \mathrm{mol}^{-1}$, followed by T8 with $285.33 \mu \mathrm{mol} \mathrm{mol}^{-1}$. The CK1 treatment had the lowest value with only $125.33 \mu \mathrm{mol} \mathrm{mol}^{-1}$. Compared with the control $\mathrm{CK}, \mathrm{C}_{\mathrm{i}}$ at the growth and maturity stages increased by 18.78\%-70.16\% and 28.19\%-118.27\%, respectively, after EMBF application. For the same fertilization rate, $\mathrm{C}_{\mathrm{i}}$ at the growth stage of the CK treatment increased as the irrigation rate increased. Under the 100, 300, and $600 \mathrm{~g}$ fertilization conditions, $\mathrm{C}_{\mathrm{i}}$ increased and then decreased, and $\mathrm{T} 5 \mathrm{had}$ the highest value. The difference between $100 \mathrm{~g}$ fertilization treatment was nonsignificant $(\mathrm{P}>0.05)$. For the 40 and $80 \mathrm{~L}$ irrigation rates, $\mathrm{C}_{\mathrm{i}}$ increased and then decreased as the fertilization rate increased; $\mathrm{T} 1$ and $\mathrm{T} 5$ had the highest values, respectively. For the $120 \mathrm{~L}$ irrigation rate, $\mathrm{C}_{\mathrm{i}}$ increased as the fertilization rate increased, and the medium and high fertilization rates were beneficial to maintain $\mathrm{C}_{\mathrm{i}}$ at a high level at the growth stage.

The $\mathrm{C}_{\mathrm{i}}$ at the maturity stage decreased more than at the growth stage. The $\mathrm{C}_{\mathrm{i}}$ of fertilization treatments at CK, 100, 300 , and $600 \mathrm{~g}$ decreased by $43.32 \%-45.27 \%, 32.93 \%-33.89 \%, 27.3 \%-33.21 \%$, and $26.78 \%-45.35 \%$, respectively. For the same fertilization rate, $\mathrm{C}_{\mathrm{i}}$ at the maturity stage increased and then decreased as the irrigation rate increased, and it reached the maximum value under medium irrigation conditions. For the same irrigation rate, $\mathrm{C}_{\mathrm{i}}$ treated with the 40 and $80 \mathrm{~L}$ irrigation rates increased and then decreased, and the highest values occurred in $\mathrm{T} 4$ and $\mathrm{T} 5$, respectively. For the $120 \mathrm{~L}$ irrigation rate, $\mathrm{C}_{\mathrm{i}}$ increased as fertilization increased. The difference between $\mathrm{T} 6$ and $\mathrm{T} 9$ was nonsignificant $(\mathrm{P}>0.05)$. 
Figure 3. Effect of different treatments on the intercellular $\mathrm{CO}_{2}$ concentration $\left(\mathrm{C}_{\mathrm{i}}\right)$.

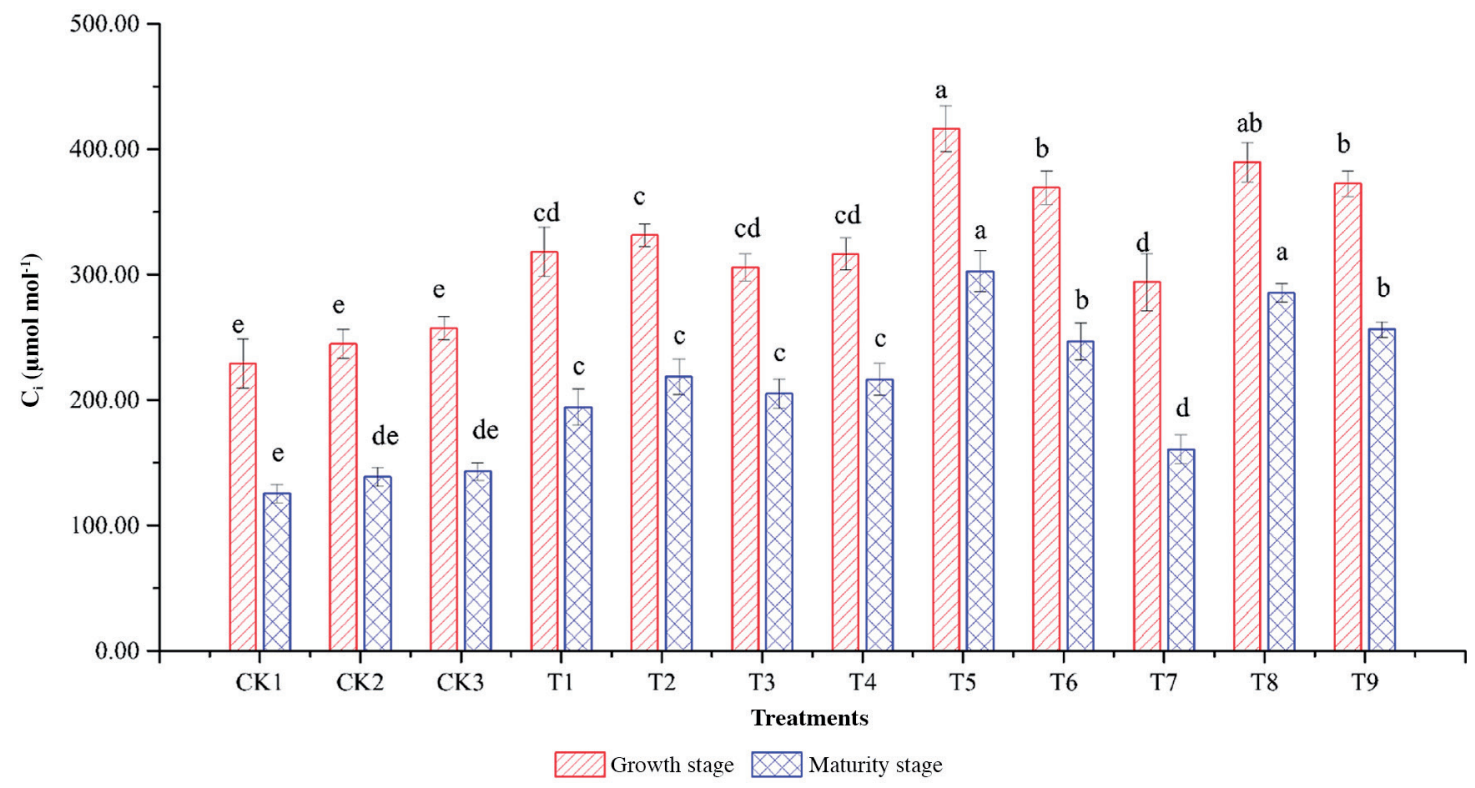

Different letters above the bars indicate significant differences $(\mathrm{P}<0.05)$ between biochar rates.

Treatments CK1-CK3, T1-T3, T4-T6, and T7-T9: Each group received 0, 100, 300, and 600 g effective microorganism biochar-based fertilizer pot $^{-1}$, respectively, and 40,80, and $120 \mathrm{~L}_{\text {irrigation }}$ pot $^{-1}$, respectively..

\section{Transpiration rate $\left(T_{r}\right)$}

The effects of different EMBF and irrigation rates on $T_{r}$ of flue-cured tobacco are shown in Figure 4. The highest $T_{r}$ value was obtained in T5 at the growth stage with $6.18 \mathrm{mmol} \mathrm{m}^{-2} \mathrm{~s}^{-1}$, followed by T9 with $5.963 \mathrm{mmol} \mathrm{m}^{-2} \mathrm{~s}^{-1}$. Treatment CK1 had the lowest value with only $3.34 \mathrm{mmol} \mathrm{m}^{-2} \mathrm{~s}^{-1}$. The same occurred at the growth stage, $\mathrm{T}_{\mathrm{r}}$ at the maturity stage had the highest value in T5 with $4.10 \mathrm{mmol} \mathrm{m}^{-2} \mathrm{~s}^{-1}$, followed by T9 with $3.97 \mathrm{mmol} \mathrm{m}^{-2} \mathrm{~s}^{-1}$ and CK1 had the lowest value with only $1.89 \mathrm{mmol} \mathrm{m}^{-2} \mathrm{~s}^{-1}$. Compared with the control CK, $\mathrm{T}_{\mathrm{r}}$ at the growth and maturity stages increased by $12.66 \%-62.15 \%$ and 7.24\%-104.15\%, respectively, after EMBF application. Under the CK, 100, and $600 \mathrm{~g}$ fertilization conditions, $\mathrm{T}_{\mathrm{r}}$ at the growth stage increased as the irrigation rate increased and these values were significantly different $(\mathrm{P}<0.05)$. For the 300 $\mathrm{g}$ fertilization rate, $\mathrm{T}_{\mathrm{r}}$ increased and then decreased, and $\mathrm{T} 5 \mathrm{had}$ the highest value. Under the same irrigation conditions, $\mathrm{T}_{\mathrm{r}}$ for the 40 and $120 \mathrm{~L}$ irrigation rates was positively correlated with the fertilization rate, but increased and then decreased for the $80 \mathrm{~L}$ irrigation rate.

The $T_{\mathrm{r}}$ value of flue-cured tobacco at the maturity stage decreased more than at the growth stage. The $\mathrm{T}_{\mathrm{r}}$ values of the $0,100,300$, and $600 \mathrm{~g}$ fertilization rates decreased by $43.57 \%-47.29 \%, 40.87 \%-46.28 \%, 31.94 \%-34.02 \%$. and $30.82 \%-$ $35.98 \%$, respectively. For the 0,100 , and $600 \mathrm{~g}$ fertilization rates, $\mathrm{T}_{\mathrm{r}}$ of flue-cured tobacco at the maturity stage increased as irrigation increased. For the $300 \mathrm{~g}$ fertilization rate, $\mathrm{T}_{\mathrm{r}}$ at the maturity stage increased and then decreased, and $\mathrm{T} 5 \mathrm{had}$ the highest value, which was not significantly different from $\mathrm{T} 6(\mathrm{P}>0.05)$. The $\mathrm{T}_{\mathrm{r}}$ value for the 40 and $120 \mathrm{~L}$ irrigation rates waspositively correlated with the fertilization rate, while with the $80 \mathrm{~L}$ rate increased and then decreased.

Tables 2 and 3 show the correlation analysis results between the main photosynthetic characteristic indicators of flue-cured tobacco at the growth and maturity stages and irrigation and fertilization rates. Table 2 shows that $P_{n}, g_{s}, C_{i}$, and $T_{r}$ were significantly and positively correlated with the EMBF rate at the growth stage $(P<0.01, R=0.567,0.673$, 0.615 , and 0.650 , respectively). The $P_{n}, g_{s}$, and $T_{r}$ were all highly significant and positively correlated with the irrigation rate $\left(P<0.01, R=0.543,0.519\right.$, and 0.517 , respectively). Table 3 shows tht $P_{n}, g_{s}, C_{i}$, and $T_{r}$ were highly significant and positively correlated with the EMBF application rate at the maturity stage $(\mathrm{P}<0.01, \mathrm{R}=0.624,0.727,0.573$, and 0.729 , respectively). The $\mathrm{P}_{\mathrm{n}}, \mathrm{g}_{s}$, and $\mathrm{T}_{\mathrm{r}}$ were significantly and positively correlated with the irrigation rate $(\mathrm{P}<0.05, \mathrm{R}=0.372$, 0.410 , and 0.401 , respectively). 
Figure 4. Effect of different treatments on the transpiration rate $\left(T_{r}\right)$.

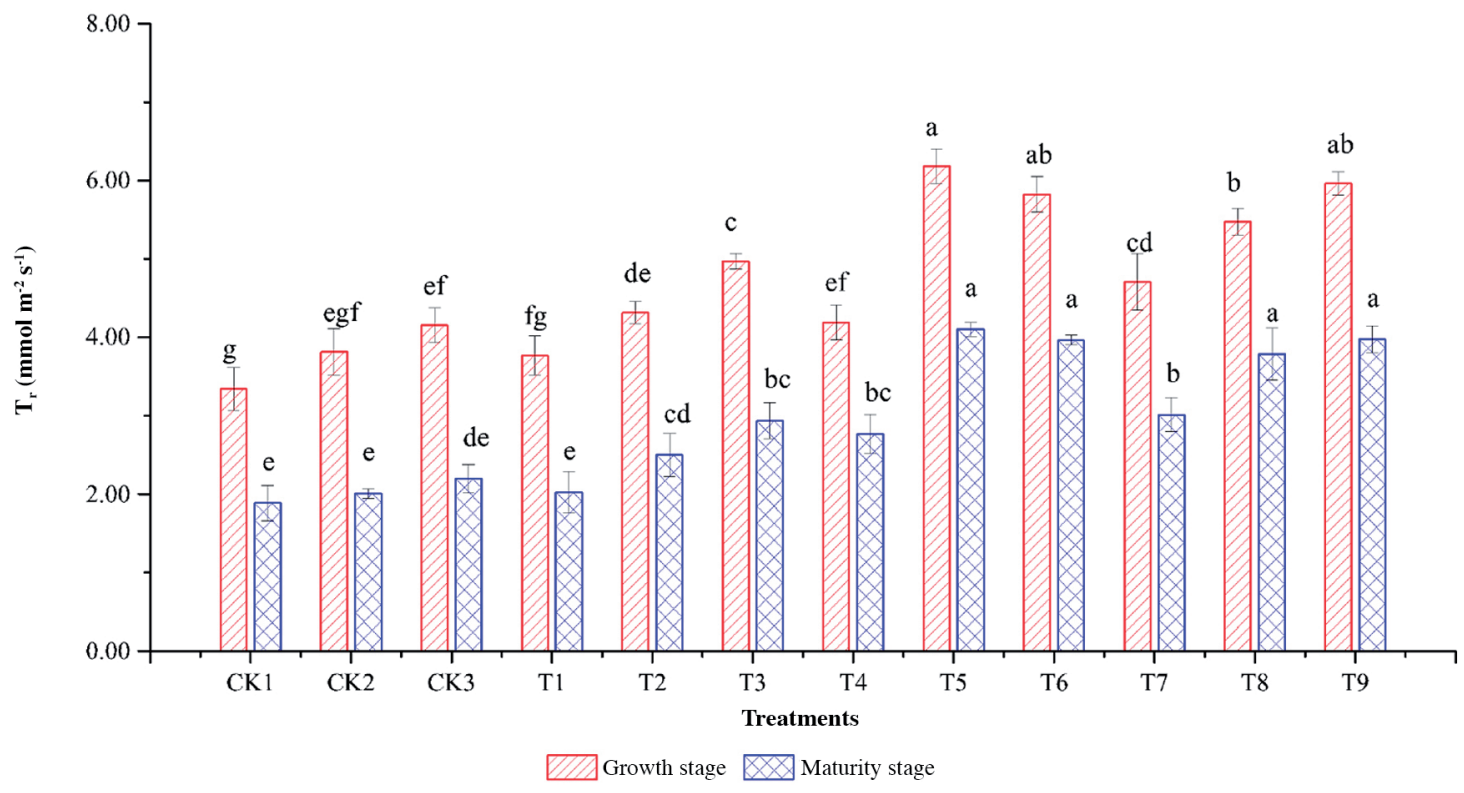

Different letters above the bars indicate significant differences $(\mathrm{P}<0.05)$ between biochar rates.

Treatments CK1-CK3, T1-T3, T4-T6, and T7-T9: Each group received 0, 100, 300, and $600 \mathrm{~g}$ effective microorganism biochar-based fertilizer pot $^{-1}$, respectively, and 40,80, and $120 \mathrm{~L}_{\text {irrigation }}$ pot $^{-1}$, respectively.

Table 2. Correlation analysis of main photosynthetic indices, EMBF application and irrigation rates at the growth stage.

\begin{tabular}{lcccccc}
\hline Parameter & EMBF & $\mathrm{I}$ & $\mathrm{P}_{\mathrm{n}}$ & $\mathrm{g}_{\mathrm{s}}$ & $\mathrm{C}_{\mathrm{i}}$ & $\mathrm{T}_{\mathrm{r}}$ \\
\hline EMBF & 1 & 0.000 & $0.567 \mathrm{~b}$ & $0.673 \mathrm{~b}$ & $0.615 \mathrm{~b}$ & $0.650 \mathrm{~b}$ \\
$\mathrm{I}$ & & 1 & $0.543 \mathrm{~b}$ & $0.519 \mathrm{~b}$ & 0.232 & $0.517 \mathrm{~b}$ \\
$\mathrm{P}_{\mathrm{n}}$ & & & 1 & $0.928 \mathrm{~b}$ & $0.826 \mathrm{~b}$ & $0.922 \mathrm{~b}$ \\
$\mathrm{~g}_{\mathrm{s}}$ & & & & 1 & $0.831 \mathrm{~b}$ & $0.918 \mathrm{~b}$ \\
$\mathrm{C}_{\mathrm{i}}$ & & & & & 1 & $0.837 \mathrm{~b}$ \\
$\mathrm{~T}_{\mathrm{r}}$ & & & & & & 1 \\
\hline
\end{tabular}

a: Significant at $\mathrm{P}=0.05$; b: significant at $\mathrm{P}=0.01$.

EMBF: Effective microorganism biochar-based fertilizer; I: irrigation; $\mathrm{P}_{\mathrm{n}}$ : net photosynthetic rate; $\mathrm{g}_{\mathrm{s}}$ : stomatal conductance; $\mathrm{C}_{\mathrm{i}}$ : intercellular $\mathrm{CO}_{2}$ concentration; $\mathrm{T}_{\mathrm{r}}$ : transpiration rate.

Table 3. Correlation analysis of main photosynthetic indices, EMBF application and irrigation rates at the maturity stage.

\begin{tabular}{lcccccc}
\hline Parameter & EMBF & $\mathrm{I}$ & $\mathrm{P}_{\mathrm{n}}$ & $\mathrm{g}_{\mathrm{s}}$ & $\mathrm{C}_{\mathrm{i}}$ & $\mathrm{T}_{\mathrm{r}}$ \\
\hline $\mathrm{EMBF}$ & 1 & 0.000 & $0.624 \mathrm{~b}$ & $0.727 \mathrm{~b}$ & $0.573 \mathrm{~b}$ & $0.729 \mathrm{~b}$ \\
$\mathrm{I}$ & & 1 & $0.372 \mathrm{a}$ & $0.410 \mathrm{a}$ & 0.247 & $0.401 \mathrm{a}$ \\
$\mathrm{P}_{\mathrm{n}}$ & & & 1 & $0.928 \mathrm{~b}$ & $0.879 \mathrm{~b}$ & $0.905 \mathrm{~b}$ \\
$\mathrm{~g}_{\mathrm{s}}$ & & & & 1 & $0.837 \mathrm{~b}$ & $0.919 \mathrm{~b}$ \\
$\mathrm{C}$ & & & & & 1 & $0.839 \mathrm{~b}$ \\
$\mathrm{~T}_{\mathrm{r}}$ & & & & & & 1 \\
\hline
\end{tabular}

a: Significant at $\mathrm{P}=0.05$; $\mathrm{b}$ : significant at $\mathrm{P}=0.01$.

EMBF: Effective microorganism biochar-based fertilizer; I: irrigation; $\mathrm{P}_{\mathrm{n}}$ : net photosynthetic rate; $\mathrm{g}_{\mathrm{s}}$ : stomatal conductance; $\mathrm{C}_{\mathrm{i}}$ : intercellular $\mathrm{CO}_{2}$ concentration; $\mathrm{T}_{\mathrm{r}}$ : transpiration rate.

\section{Effects on chlorophyll content}

Figure 5 shows the SPAD values of flue-cured tobacco at different growth stages for the 0, 100, 300, and $600 \mathrm{~g}$ EMBF application rates. Different treatments had higher SPAD values at the growth stage, and there was a slight difference between the rooting and maturity stages. Compared with the control CK, the SPAD values at the growth and maturity stages increased by 3.47\%-26.36\% and 5.25\%-69.09\%, respectively, after EMBF application. For the $0 \mathrm{~g}$ fertilization application rate (Figure 5a), the ranges of SPAD values at the rooting, growth, and maturity stages were 16.57-20.63, 
Figure 5. Effect of different treatments on soil plant analysis development (SPAD) values at different growth stages.
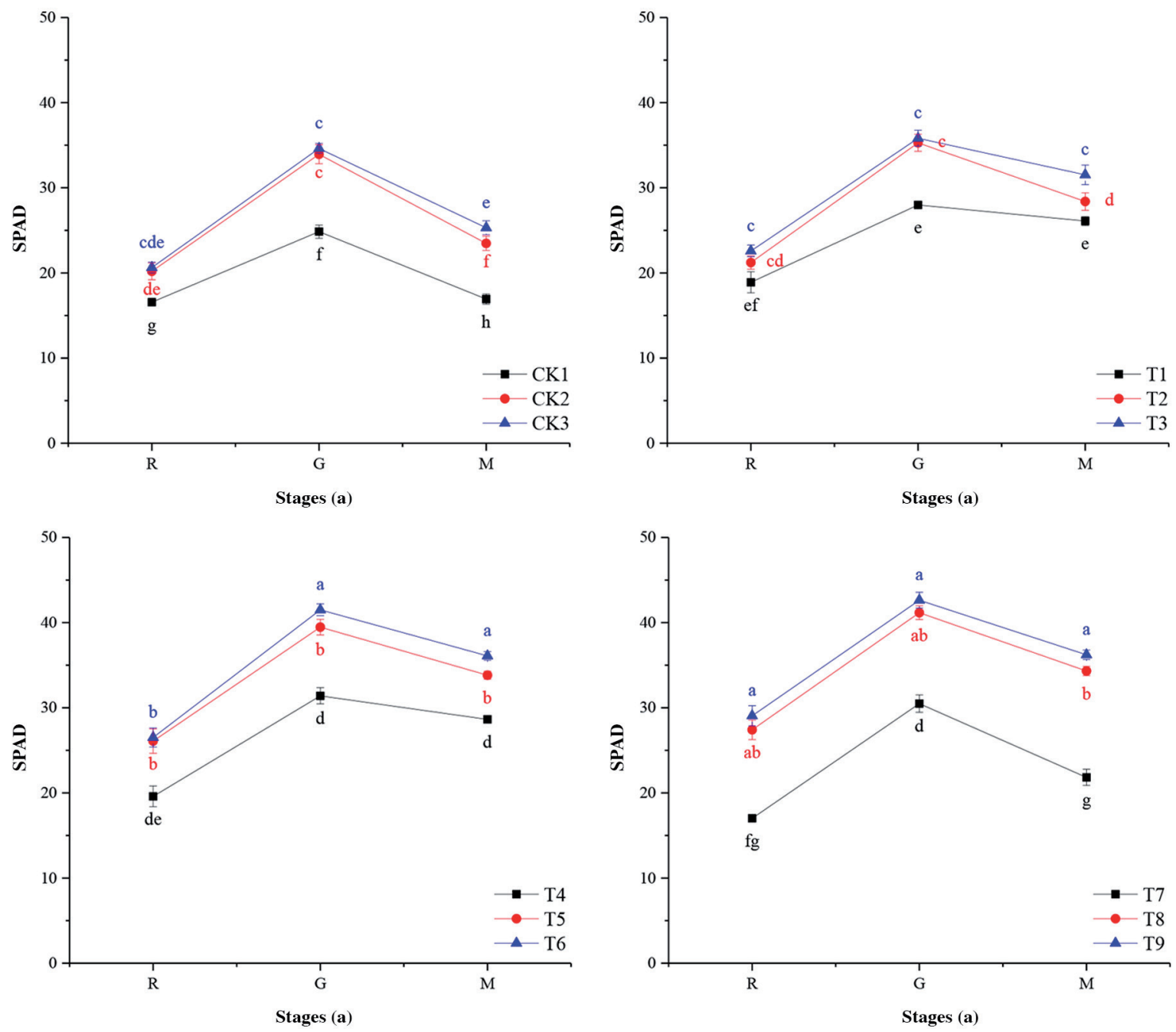

Different letters above the bars indicate significant differences $(\mathrm{P}<0.05)$ between biochar rates.

R: Rooting stage; G: growth stage; M: maturity stage.

Treatments CK1-CK3, T1-T3, T4-T6, and T7-T9: Each group received 0, 100, 300, and $600 \mathrm{~g}$ effective microorganism biochar-based fertilizer pot $^{-1}$, respectively, and 40, 80, and $120 \mathrm{~L}$ irrigation pot $^{-1}$, respectively.

24.85-34.62, and 16.93-25.3, respectively, which all increased as irrigation increased. The SPAD values for CK1, CK2, and CK3 at the maturity stage decreased by $31.86 \%, 30.83 \%$, and $26.91 \%$, respectively, compared with the growth stage. For the $100 \mathrm{~g}$ fertilization rate (Figure 5b), the ranges of SPAD values at the rooting, growth, and maturity stages were 18.9-22.58, 27.98-35.82, and 26.1-31.52, respectively, which all increased as irrigation increased. The SPAD values for $\mathrm{T} 1, \mathrm{~T} 2$, and $\mathrm{T} 3$ at the maturity stage decreased by $6.73 \%, 19.54 \%$, and $11.99 \%$, respectively, compared with the growth stage, and T1 had a slight decrease. For the $300 \mathrm{~g}$ fertilization rate (Figure 5c), the ranges of SPAD values at the rooting, growth, and maturity stages were 19.59-26.51,31.4-41.5, and 28.63-36.09, respectively, which all increased as irrigation increased. The SPAD values of T4, T5, and T6 at the maturity stage decreased by $8.81 \%, 14.30 \%$, and $13.04 \%$, respectively, compared with the growth stage, which was slightly lower than in other fertilization treatments. For the 600 $\mathrm{g}$ fertilization rate (Figure 5d), the ranges of SPAD values at the rooting, growth, and maturity stages were 17.01-29.06, 30.48-42.63, and 21.82-36.22, respectively, which all increased as irrigation increased. Treatment T9 had the highest SPAD value at all three growth stages and was significantly different from the other treatments. The SPAD values for $\mathrm{T} 7, \mathrm{~T} 8$, and $\mathrm{T} 9$ at the maturity stage decreased by $28.41 \%, 16.63 \%$, and $15.04 \%$, respectively, compared with the growth stage and $\mathrm{T} 7 \mathrm{had}$ a higher decrease. 
Table 4 shows the correlation analysis results between SPAD values, EMBF application and irrigation rates of fluecured tobacco at different growth stages. The irrigation rate was the main factor influencing the SPAD value at the three growth stages. The SPAD value at the rooting stage was more affected by the fertilization and irrigation rates than at the maturity stage, with correlation coefficients of 0.492 and 0.637 , respectively $(\mathrm{P}<0.01)$. The fertilization and irrigation rates had a significant influence on the SPAD value at the growth stage, with correlation coefficients of 0.495 and 0.718 , respectively $(\mathrm{P}<0.01)$, in which the effect of irrigation was greater.

\section{DISCUSSION}

Photosynthesis plays a decisive role in crop yield (Zhao et al., 2019). In the present study, it was found that appropriate EMBF application and irrigation rates could significantly increase the $\mathrm{P}_{n}, \mathrm{~g}_{s}, \mathrm{C}_{\mathrm{i}}$, and $\mathrm{T}_{\mathrm{r}}$ values of flue-cured tobacco. This indicates that EMBF could enhance the photosynthetic capacity of tobacco leaves and maintain a strong physiological metabolism, with results similar to those reported by Yang et al. (2019). Zhao et al. (2010) considered that this might be related to the water retention effect of EMBF. The EMBF can effectively control the water in the soil and release it slowly, increase soil water content around the roots, and show a lower water pressure deficit and stronger photosynthesis ability in the tobacco leaves. In the present study, the values of $P_{n}, g_{s}$ and $T_{r}$ increased as the irrigation rate increased for the 0,100 , and $600 \mathrm{~g}$ fertilization rates, and increased then decreased for the $300 \mathrm{~g}$ fertilization rate, indicating that under moderate fertilization conditions, a higher irrigation rate would limit the increase of $P_{n}, g_{s}$, and $T_{r}$ values of flue-cured tobacco. This can be due to fertilizer leaching caused by excessive irrigation (Zhang et al., 2019a), which exceeds the waterholding capacity of the applied EMBF. The excess water occupies the soil voids, squeezing out soil air, which affects the respiratory metabolism of the root system and affects root vitality of flue-cured tobacco, resulting in the photosynthetic decline of flue-cured tobacco leaves.

Studies by Li et al. (2019b) showed that both $\mathrm{P}_{\mathrm{n}}$ and $\mathrm{g}_{\mathrm{s}}$ of flue-cured tobacco seedling leaves significantly decreased, while $\mathrm{C}_{\mathrm{i}}$ increased significantly under drought stress. Hou et al. (2016) indicated that $\mathrm{C}_{\mathrm{i}}$ of flue-cured tobacco treated with EM water-retaining agents during the growth period was significantly higher than in the control treatment. In the present study, under the conditions of proper EMBF application and irrigation rates, $P_{n}, g_{s}$, and $T_{r}$ increased significantly, and differences in the values of T6, T8, and T9 were small. This was probably because $\mathrm{g}_{\mathrm{s}}$ is the limiting factor of $\mathrm{P}_{\mathrm{n}}$ (Zhao et al., 2010), and $g_{s}$ and $T_{r}$ are positively correlated, while EMBF application promotes moisture absorption of flue-cured tobacco, improves nutrient effectiveness in fertilizers, and enhances transpiration. When the irrigation and fertilization rates reach a certain level, the photosynthetic characteristics of flue-cured tobacco are no longer affected.

The value of $\mathrm{C}_{\mathrm{i}}$ was less affected by the irrigation rate, and the differences between the $\mathrm{T} 1, \mathrm{~T} 2$, and $\mathrm{T} 3$ treatments were nonsignificant. For the same fertilizer application rate, $\mathrm{C}_{\mathrm{i}}$ was higher in the treatment with the $40 \mathrm{~L}$ irrigation rate, indicating that the low fertilizer rate had nonsignificant effect on the $\mathrm{C}_{\mathrm{i}}$ value of flue-cured tobacco and the medium irrigation rate could maintain $\mathrm{C}_{\mathrm{i}}$ at a high level. However, Ma et al. (2018) showed that the $\mathrm{C}_{\mathrm{i}}$ value was positively related to the irrigation and fertilization rates, which could be because the temperature in the greenhouse was too high, the irrigation rate was excessive, soil water evaporation increased, and the soil salt return rate was accelerated (Shi et al., 2017). Leaf surface stomata were closed to reduce water evaporation, $C_{i}$ increased, and transpiration of flue-cured tobacco was weakened; this resulted in decreased water absorption capacity of the root system, which reduced the photosynthetic rate.

Table 4. Correlation analysis of SPAD values, EMBF application and irrigation rates of flue-cured tobacco at different growth stages.

\begin{tabular}{lccccc}
\hline Parameter & EMBF & $\mathrm{I}$ & $\mathrm{R}$ & $\mathrm{G}$ & $\mathrm{M}$ \\
\hline EMBF & 1 & 0.000 & $0.492 \mathrm{~b}$ & $0.495 \mathrm{~b}$ & $0.490 \mathrm{~b}$ \\
$\mathrm{I}$ & & 1 & $0.637 \mathrm{~b}$ & $0.718 \mathrm{~b}$ & $0.602 \mathrm{~b}$ \\
$\mathrm{R}$ & & 1 & $0.916 \mathrm{~b}$ & $0.892 \mathrm{~b}$ \\
$\mathrm{G}$ & & & 1 & $0.895 \mathrm{~b}$ \\
M & & & & & 1 \\
\hline
\end{tabular}

a: Significant at the 0.05 level; b: significant at the 0.01 level.

SPAD: Soil plant analysis development; EMBF: effective microorganism biochar-based fertilizer;

I: irrigation; R: rooting stage; G: growth stage; M: maturity stage. 
Chlorophyll is the basis of photosynthesis, which can be used as a guide for timely fertilization to meet the needs of tobacco growth, improve fertilizer use efficiency, and minimize fertilizer waste and environmental pollution caused by excessive fertilization (Wei et al., 2012). It can also be used as a diagnostic indicator of the quality of flue-cured tobacco leaves (Fracchiolla et al., 2020). For the same irrigation rate, the SPAD value increased as fertilization increased; this might be because the absorption of $\mathrm{N}$ in the base fertilizer by flue-cured tobacco was promoted after EMBF application (Bai et al., 2013), thereby increasing the SPAD value. For the same fertilization rate, the SPAD value increased as the irrigation rate increased, which is consistent with the results of the study by Neupane et al. (2020). Among treatments, the treatment with high irrigation and high fertilizer application rates (T9) had the highest SPAD value during the three growth stages. This can be due to the good water retention performance of EMBF, which can ensure that the root system of flue-cured tobacco absorbs sufficient water; the mesophyll cells promote chlorophyll synthesis when there is sufficient water, which increases the total amount of chlorophyll inside the leaves. The experimental results also complement the research conducted by Du et al. (2019).

\section{CONCLUSIONS}

It could be concluded from the results that the water-fertilizer management approach with the appropriate irrigation rate and effective microorganism biochar-based fertilizer (EMBF) application rate could significantly improve the photosynthetic characteristics and chlorophyll content of flue-cured tobacco. Compared with the control CK, the net photosynthetic rate $\left(\mathrm{P}_{\mathrm{n}}\right)$, stomatal conductance $\left(\mathrm{g}_{\mathrm{s}}\right)$, intercellular $\mathrm{CO}_{2}$ concentration $\left(\mathrm{C}_{\mathrm{i}}\right)$, and transpiration rate $\left(\mathrm{T}_{\mathrm{r}}\right)$ increased by $8.21 \%-107.03 \%$, $18.78 \%-118.27 \%, 18.78 \%-118.27 \%$, and $7.24 \%-104.15 \%$, respectively, after the EMBF application. The $\mathrm{P}_{n}, \mathrm{~g}_{\mathrm{s}}, \mathrm{C}_{\mathrm{i}}$, and $\mathrm{T}_{\mathrm{r}}$ at the growth and maturity stages were highly significant and positively correlated with the EMBF application rate. The $\mathrm{P}_{\mathrm{n}}, \mathrm{g}_{\mathrm{s}}$, and $T_{r}$ were significant and positively correlated with the irrigation rate, and $C_{i}$ was less affected by irrigation.

The soil plant analysis development (SPAD) value of flue-cured tobacco in three plant growth stages was highly significant and positively correlated with the irrigation and fertilization rates. Compared with the control, the SPAD values at the growth and maturity stages increased by $3.47 \%-26.36 \%$ and $5.25 \%-69.09 \%$, respectively, after the EMBF application. The SPAD values at the growth and maturity stages were higher than at the rooting stage by $46.73 \%-79.2 \%$ and $2.21 \%-46.17 \%$, respectively. Higher EMBF application and irrigation rates were beneficial to maintain a high SPAD value. Furthermore, the $80 \mathrm{~L} \mathrm{pot}^{-1}$ irrigation rate and $300 \mathrm{~g} \mathrm{pot}^{-1} \mathrm{EMBF}$ application rate is the best water and fertilizer combination. The results of this study might provide theoretical and practical guidance for the growth of flue-cured tobacco in production areas. Different varieties of flue-cured tobacco need to be studied in the future to improve the universality of the research results.

\section{ACKNOWLEDGEMENTS}

This work was financially supported by the Science and Technology Project of Guizhou Tobacco of the China National Tobacco Corporation (201709), Postgraduate Research \& Practice Innovation Program of Jiangsu Province (SJKY19_0520), the Fundamental Research Funds for the Central Universities (2019B68214), and the Science and Technology Project of the Tobacco Company of the Southwest of Guizhou Province (JS-JL-11/D 201502).

\section{REFERENCES}

Bai, Z.G., Luo, Y.Y., Ji, S.G., Chen, F.R., Quo, Z.X., Liu, Q.G., et al. 2013. Effects of effective microorganisms pretreatment on nitrogen transformation of fresh waste leaves of tobacco during anaerobic fermentation. Southwest China Journal of Agricultural Sciences 26(5):2026-2029.

Chen, Y., Lin, Y.C., Huang, H.G., Lin, Y.C., Gao, W.C., and Pan, W.J. 2019. Effect of biochar-based fertilizer on properties of tobacco-planting yellow soil, and nutrient accumulation, yield and quality of flue-cured tobacco. Acta Pedologica Sinica 56(02):495-504

Chen, J.N., Shao, X.H., Zhai, Y.M., Hou, M.M., Zhao, T.C., and Wang, G. 2017. The effect of mulching drip irrigation and water-nitrogen coupling on water and fertilizer use of flue-cured tobacco and nutrient content of soil. Water Saving Irrigation 12:68-71.

Dai, S., Su, Y.Y., Sun, H.Y., and Li, S.X. 2019. Effects of effective microorganisms on growth of container seedlings of Quercus shumardii. Journal of Northeast Forestry University 47(10):20-23. 
Daly, M.J., and Stewart, D.P.C. 1999. Influence of 'effective microorganisms' (EM) on vegetable production and carbon mineralization-A preliminary investigation. Journal of Sustainable Agriculture 14(2-3):15-25.

Du, C.Y., Wang, D.Q., Xia, L., Gao, Z.X., Xi, Y.X., Fang, M., et al. 2019. Effects of nitrogen reduction and fertilization on agronomic characteristics and chlorophyll content of flue-cured tobacco under drip irrigation. Journal of Zhejiang Agricultural Sciences 60(6):957-962.

Fracchiolla, M., Renna, M., D’Imperio, M., Lasorella, C., Santamaria, P., and Cazzato, E. 2020. Living mulch and organic fertilization to improve weed management, yield and quality of broccoli raab in organic farming. Plants 9(2):177.

Higa, T., and Parr, J. 1994. Beneficial and effective for a sustainable agriculture. Agriculture 808:1-16.

Hou, M.M., Shao, X.H., Chen, J.N., Zhai, Y.M., Zhao, T.C., and Wang, G. 2016. Optimization of EM water-retention agent application in flue-cured tobacco. Chinese Journal of Eco-Agriculture 24(5):628-636.

Hu, C., and Qi, Y.C. 2013. Long-term effective microorganisms application promote growth and increase yields and nutrition of wheat in China. European Journal of Agronomy 46:63-67.

Kulik, M.C., Bialous, S.A., Munthali, S., and Max, W. 2017. Tobacco growing and the sustainable development goals, Malawi. Bulletin of the World Health Organization 95(5):362-367.

Li, C.B., Fu, D.L., Cao, T.M., Zhang, L.C., Hen, X., and Chen, Y. 2019a. Effects of carbon-based compound fertilizer formula on soil enzyme activity and characteristic of physiology, nutrient accumulation and yield of flue-cured tobacco. Hunan Agricultural Sciences 07:48-54.

Li, X., He, L., Zhang, X., and Song, T. 2008. Changes in soil enzyme activity and fertility of cucumber planted organic nutrient soil. Journal of Soil Science 39(3):524-527.

Li, D., Shen, H.T., Wang, Y.F., Wang, L.J., Zhao, S.M., and Liu, L. 2019b. Effect of exogenous hydrogen sulfide on photosynthetic fluorescence parameters and antioxidant system of flue-cured tobacco seedlings under drought stress. Acta Botanica Boreali-Occidentalia Sinica 39(9):1609-1617.

Ma,G.L.,Zhang, G.B., Qiang,H.R.,Zhang,B.Y.,Ji,L.,Li,J., et al.2018. Effects of water and nitrogen coupling on growth, photosynthetic characteristics and nutrient allocation of pepper in solar greenhouse. Agricultural Research in the Arid Areas 36(5):130-141.

Neupane, D., Solomon, J.K.Q., Mclennon, E., Davison, J., and Lawry, T. 2020. Camelina production parameters response to different irrigation regimes. Industrial Crops and Products 148:112286.

Qin, P., Wang, H.L., Yang, X., He, L.Z., Müller, K., Shaheen, S.M., et al. 2018. Bamboo- and pig-derived biochars reduce leaching losses of dibutyl phthalate, cadmium, and lead from co-contaminated soils. Chemosphere 198:450-459.

Shi, W.J., He, Z.J., and Xu, F. 2017. Changes of soil temperature and water supply from groundwater to crop under different irrigation amount with drip irrigation under plastic mulch. Journal of Soil and Water Conservation 31(2):117-121.

Shin, K., van Diepen, G., Blok, W., and van Bruggen, A.H.C. 2017. Variability of effective micro-organisms (EM) in bokashi and soil and effects on soil-borne plant pathogens. Crop Protection 99:168-176.

Talaat, N.B., Ghoniem, A.E., Abdelhamid, M.T., and Shawky,B.T.2015. Effective microorganisms improve growth performance, alter nutrients acquisition and induce compatible solutes accumulation in common bean (Phaseolus vulgaris L.) plants subjected to salinity stress. Plant Growth Regulation 75(1):281-295.

Wang, X.Q., Xu, Y.Q., He, X.B., Mao, J., Zhang, K., Xu, F.D., et al. 2019. Effects of applying biochar based fertilizer with nitrogen reduction on yield and quality of flue-cured tobacco in Central Henan tobacco-growing region. Guizhou Agricultural Sciences 47(2):32-36.

Wei, B., Zeng, F.D., Lin, J.W., Li, F.J., Yang, T.X., Cao, N., et al. 2012. Effects of SPAD value-based field nitrogen management on leaf development and yield of flue-cured tobacco. Guangdong Agricultural Sciences 39(16):13-16.

Xie, Z., Shao, X.H., Duan, W.D., Li, H.L., and Shi, H.Z. 2019. Research and application advances in fertigation technology in flue-cured tobacco production. Soils 51(2):235-242.

Xue, R.J., Gao, T., Ma, E.D., Jin, Y., and Zhao, Z.X. 2019. Effects of fertigation method and fertilizer amount on the growth, N, $\mathrm{P}, \mathrm{K}$ utilization, and yield of flue-cured tobacco. Journal of Irrigation and Drainage 38(08):22-30.

Yang, X., Shao, X., Mao, X., Li, M., Zhao, T., Wang, F., et al. 2019. Influences of drought and microbial water-retention fertilizer on leaf area index and photosynthetic characteristics of flue-cured tobacco. Irrigation and Drainage 68(4):729-739.

Ye, X.F., Li, Z.P., Yu, X.N., Niu, Y.D., Li, X.F., Guan, S.S., et al. 2015. Effect of biochar application rate on quality of fluecured tobacco leaves and carbon pool in tobacco growing soil. Acta Tabacaria Sinica 21(5):33-41.

Zhang, Z.H., Chen, S.M., Ren, T.B., Ding, S.S., Li, Y., Wang, H.H., et al. 2019b. Effects of high-carbon base fertilizer on the growth of flue-cured tobacco and diversity of soil microbial carbon metabolism. Soils and Fertilizers Sciences in China (1):79-86.

Zhang, Y.F., Liu, Y.Y., Du, C.X., and Xiao, G.J. 2019a. Study of drought monitoring evaluation model during tobacco transplanting and its application. Southwest China Journal of Agricultural Sciences 32(2):286-290.

Zhao, K.N., Zhang, B.J., Wang, D.M., Tao, Z.Q., Wang, Y.J., Yang, Y.S., et al. 2019. Optimum nitrogen topdressing time for improving photosynthetic efficiency and yield of tridimensional uniform sowing winter wheat. Plant Nutrition and Fertilizer Science 25(8):1354-1361.

Zhao, M.Q., Zhao, J.H., Zhang, D., Han, F.G., Zhang, G.F., Li, Y.S., et al. 2010. Effects of water retention agent on diurnal changes of photosynthetic characteristics in flue-cured tobacco. Scientia Agricultura Sinica 43(6):1265-1273.

Zhu, Q., Kong, L.J., Xie, F.T., Zhang, H.J., Wang, H.Y., and Ao, X. 2018. Effects of biochar on seedling root growth of soybeans. Chilean Journal of Agricultural Research 78:549-558. 